\title{
Prevalence of overweight, obesity and hypertension amongst school children and adolescents in North Karnataka: A cross sectional study
}

$\frac{1}{0}$
$\frac{\pi}{0}$
$\frac{7}{4}$
$\frac{7}{1}$

Ravikumar V. Baradol, S.V. Patil, Anand Ranagol

Department of Paediatrics,

B. L. D. E. U'S S. B. M. Patil Medical College, Shri Bangarappa Sajjan Complex, Solapur Road,

Bijapur, Karnataka, India

Address for the Correspondence:

Dr. Ravikumar Vasant Baradol, Department of Paediatrics, B. L.

D. E. U'S S. B. M. Patil Medical College, Shri Bangarappa Sajjan Complex, Solapur Road, Bijapur, Karnataka, India. E-mail: ravikumar8901@gmail. com

\begin{tabular}{|l|}
\hline Access this article online \\
\hline Website: www.ijmedph.org \\
\hline DOI: 10.4103/2230-8598.137713 \\
\hline Quick response code: \\
\hline
\end{tabular}

Introduction: Childhood obesity\& hypertension are global health problems as they caused increase in morbidity \& mortality. Objective: To find out the prevalence of obesity, overweight in school going children and adolescents of north Karnataka. Also to study obesity related morbidities like Prehypertension and Hypertension and associated risk factors for sustained hypertension. Materials and Methods: Total 2800 children in age group from 10-16 years from 3 schools of Urban and rural region of Bijapur district were screened. Weight, height, $\mathrm{BMI}$ and Blood pressure were recorded. These values were compared with WHO child growth standards. Children then classified as overweight (OW) and obesity (OB). Blood pressure values were compared with reference charts given by American heart association guidelinesand grouped as prehypertensive (PHTN) and Hypertension (HTN). Results: This study revealed that $3.6 \%$ rural school children were overweight (OW) in age group of 13 years, $1.4 \%$ children were obese $(O B)$ in age group of 15 years. In urban school children, $3.3 \%$ OB in age group of 12 years and $11.1 \% \mathrm{OW}$ in age group of 10 years. In Rural school children, prevalence of systolic HTN was $21 \%$ in OW children and $25 \%$ in OB children. Among urban schoolchildren prevalence of systolic PHTN was $5.1 \%$ among OW and in OB group it was $16.6 \%$. Conclusions: This study revealed that prevalence of hypertension was significantly higher in overweight and obese compared to children with Normal BMI. Also the prevalence of overweight and obesity is more in urban school children than rural children population. We need further large scale studies to study obesity and associated morbidities like hypertension school children and adolescents.

Key words: Body mass index (BMI), Hypertension (HTN), India, North Karnataka, Obese (OB), Overweight (OW), Prehypertension (PHTN)

\section{INTRODUCTION}

Obesity, overweight and hypertension in school children and adolescents are emerging as newer health problems in developing countries like India. The magnitude of overweight ranges from 9 to $27.5 \%$ and obesity ranges from 1 to $12.9 \%$ among Indian children. ${ }^{[1-4]}$ Overweight and obesity are increasingly prevalent nutritional disorder among children and adolescents in the world. ${ }^{[5]}$ Presently in India also there is sharp rise in number of children and adolescents with obesity. Overweight children have a greater chance of becoming overweight adolescents and obese adults compared to children of normal weight. ${ }^{[6]}$ The severity of obesity and age of onset affect the likelihood of persistence of obesity into adulthood and thus entrainment of obesity induced morbidities like prehypertension and hypertension. ${ }^{[7]}$ Numerous health problems are associated with adolescent overweight including hypertension, respiratory disease, several orthopaedic disorders, diabetes mellitus and elevated serum lipid concentrations. ${ }^{\left[{ }^{[8]}\right.}$ Obese children are also reported to have increased heart rate variability ${ }^{[0]}$ and blood pressure variability. ${ }^{[25]}$

In the developed countries, the prevalence of obesity and hypertension is increasing. Various studies are available which demonstrate the burden of these non communicable diseases. ${ }^{[2,3,6]}$ 
There has been lack of standard definitions of overweight and obesity. The current lack of consistency and agreement between different studies over the classification of obesity and overweight in children and adolescents makes it difficult to an overview of global prevalence of overweight and obesity. Now international cut off points for classification of obesity and overweight have been published. ${ }^{[6]}$ So, we decided to carry out the study using these as reference standard values.

To prevent non communicable diseases like hypertension, obesity primordial prevention is very essential. So we decided to measure prevalence of hypertension and obesity in children.

\section{OBJECTIVES OF STUDY}

1. To find out prevalence of obesity, overweight in school going children and adolescents of north Karnataka.

2. To study obesity related morbidities like Prehypertension and Hypertension and associated risk factors for sustained hypertension among school children $\&$ adolescents.

\section{MATERIALS AND METHODS}

It was a cross sectional study done on school children in the age group of 10 to 16 years so that we can study more on an adolescent health problems and also get co-operation from children for recording BP and other parameters. Children were selected from Urban and Rural areas in and around Bijapur City which is part of north Karnataka. Since the data regarding the prevalence of obesity, overweight and hypertension in developing part of India is lacking. Therefore, Bijapur which is situated at north Karnataka of India was selected as study place.

As per availability data from Bijapur Municipal Corporation around 84000 children were studying in schools. Considering prevalence of hypertension of $11 \%$ in school going children ${ }^{[38-41]}$ and $20 \%$ sampling error, 1400 school children from urban area and rural area each in the age group of 10 to 16 years were included under this study. Children with systemic diseases like renal diseases (like PCKD), acute illness, known hypertensives, children on medications which can alter BP readings were excluded from the study because we want to study essential hypertension in children and the impact of obesity on blood pressure in children.

Data was collected in a pretested proforma meeting the objective of the study. This proforma was screened and approved by institutional ethics committee. Informed consent was taken from the parents of all children before conducting school survey and BP measurement.

The age of the school children was obtained from the school records. The name and other particulars were entered in a pretested proforma. Height was measured by making the child to stand upright barefoot, on the ground with heels, buttocks and shoulder touching the wall and head in Frankfurt plane. The height was measured using a sliding stadiometer (Johnson and Johnson) with an accuracy of
$0.1 \mathrm{~mm}$. Weight was recorded using a spring balance (bathroom scale) calibrated to $0.5 \mathrm{~kg}$ accuracy. Body mass index (BMI) was calculated using formula Weight $(\mathrm{Kg}) /$ Height $\left(\mathrm{m}^{2}\right)$ and values are compared with WHO Growth charts. ${ }^{[10]}$ Children with a body mass index (BMI) $>85$ th percentile of reference data were considered overweight and those with a $\mathrm{BMI}>95$ th percentile were considered obese. ${ }^{[11]}$

Permission was taken from each Head of the Institution prior to examining school children. Blood pressure was measured in all 10 to 16 years school children between $8 \mathrm{am}$ to $11 \mathrm{am}$ after giving $10 \mathrm{~min}$ of rest.Blood pressure was recorded by interns and residents with children in sitting position with both the hands resting on the examining table and the cubital fossa supported at the level of the heart. BP was measured after applying an appropriate sized cuff on the right arm encircling $2 / 3^{\text {rd }}$ circumference of the arm with lower edge $2.5 \mathrm{~cm}$ above the cubital fossa (as per who guidelines). ${ }^{[12]}$ The $\mathrm{BP}$ measurement was done on the right arm for consistency and comparison with standard tables. Blood pressure was recorded as per American Heart Association Guidelines. ${ }^{[12]}$ Systolic blood pressure was determined as appearance of $1^{\text {st }}$ Korotkoff sounds and diastolic blood pressure was taken at the point of muffling of heart sounds ( $4^{\text {th }}$ Korotkoff sounds). Three measurements were taken at an interval of 5 min each and mean of these readings were taken as average systolic blood pressure and average diastolic blood pressure. Blood pressure values were compared to the values given by the update of 1987 task force report of the National high blood pressure Education Programme Co-ordinating Committee. ${ }^{[13]}$ Children were classified into three groups as follows (as per guidelines of the above committee):

- $\quad$ BP $<90^{\text {th }}$ percentile - Normal $(\mathrm{N})$ Blood pressure (compared to age, sex and height percentile in each age group)

- $\quad \mathrm{BP}=90-95^{\text {th }}$ percentile- Prehypertension $(\mathrm{PHTN})$

- $\quad \mathrm{BP}>95^{\text {th }}$ percentile - Hypertension $(\mathrm{HTN})$

In those children, whose systolic and or diastolic BP value was found to be more than $95^{\text {th }}$ percentile for age, sex and height, two sets of BP reading were taken at an interval of 4 weeks. ${ }^{[42]}$ If systolic and or diastolic BP was found to be persistently more than $95^{\text {th }}$ percentile for age, sex, and height then child was classified as having sustained hypertension. Those children who had sustained hypertension were subjected to further investigations with informed parental consent. Investigations were done after taking consent from the parents in a format, after explaining the parents about the need for investigations and treatment aspects. Following investigations were done: Lipid profile, Blood Urea/serum creatinine, Urine albumin, urine sugar, urine microscopy, USG of abdomen.

\section{STATISTICAL ANALYSIS}

Data were analyzed for prevalence rate, Frequency distribution and Pearsons correlation. All the statistical operations were done through SPSS (Statistical Presentation System Software) for Windows, version 10.0 (SPSS, 1999. SPSS Inc: New York). $P<0.05$ was considered as significant. 


\section{RESULTS}

In the present study, 1400 Rural \& 1400 urban school children were screened. Total 2800 children were screened.

Data analysis revealed that, [Table 1] prevalence of obesity was $1.4 \%$ in 15 years of age group and overweight was predominantly seen in the 13 years of age group $(3.6 \%)$ in rural school children. In case of urban school children [Table 2] Obesity was predominantly seen in 12 years of age group $(3.3 \%$ ) with $11.1 \%$ of overweight children in 10 years age group.

When systolic BP and BMI of children are correlated [Table 3], we found that, in rural school children, the prevalence of prehypertension in overweight was $21 \%$ and prevalence of hypertension was $25 \%$. In obese rural school children, the Prevalence of systolic hypertension was $25 \%$.

In urban school children, in overweight children, the prevalence of prehypertension was $5.1 \%$ and the prevalence of hypertension was $3.4 \%$. Among obese children, the prevalence of prehypertension was $16.6 \%$ and that hypertension was $8.3 \%$. (Results were shown in table 4 )

In rural school children, Diastolic hypertension was seen $12.5 \%$ in obeseschool children, compared to $8.6 \%$ in overweight children, as

\begin{tabular}{|c|c|c|c|c|}
\hline Age (years) & Normal (\%) & OW (\%) & OB (\%) & Total $(n)$ \\
\hline 10 & 300 (98.3) & $2(0.6)$ & $3(0.9)$ & 305 \\
\hline 11 & $239(100)$ & 0 & 0 & 239 \\
\hline 12 & 141 (97.9) & $3(2.0)$ & 0 & 144 \\
\hline 13 & $131(95)$ & $5(3.6)$ & $1(0.7)$ & 137 \\
\hline 14 & $248(97)$ & $7(2.7)$ & $1(0.3)$ & 256 \\
\hline 15 & $196(96)$ & $3(1.4)$ & $3(1.4)$ & 202 \\
\hline 16 & 114 (95.5) & $3(2.5)$ & 0 & 117 \\
\hline Total & 1369 & $23(1.6)$ & $8(0.5)$ & 1400 \\
\hline Male & $670(97.6)$ & $11(1.6)$ & $5(0.7)$ & 686 \\
\hline Female & 699 (97.8) & $12(1.6)$ & $3(0.4)$ & 714 \\
\hline Total & 1369 & 23 & 8 & 1400 \\
\hline
\end{tabular}

\begin{tabular}{|c|c|c|c|c|}
\hline Age (in years) & Normal (\%) & OW (\%) & OB (\%) & Total $(n)$ \\
\hline 10 & $250(87.4)$ & $32(11.1)$ & $4(1.3)$ & 286 \\
\hline 11 & $255(96.2)$ & $7(2.6)$ & $3(1.1)$ & 265 \\
\hline 12 & $194(92.3)$ & $9(4.2)$ & $7(3.3)$ & 210 \\
\hline 13 & 175 & 0 & 0 & 175 \\
\hline 14 & 141 (95.9) & $3(2.0)$ & $3(2.0)$ & 147 \\
\hline 15 & 188 (97.9) & $1(0.5)$ & $3(1.5)$ & 192 \\
\hline 16 & $115(92.0)$ & $6(4.8)$ & $4(3.2)$ & 125 \\
\hline Total & 1318 & 58 & 24 & 1400 \\
\hline Male & $722(94.6)$ & $32(4.1)$ & $9(1.1)$ & 763 \\
\hline Female & $596(93.5)$ & $26(4.0)$ & $15(2.3)$ & 637 \\
\hline Total & 1318 & 58 & 24 & 1400 \\
\hline
\end{tabular}

*Values are in absolute no. \& percentage shown in table 5 . While in urban school children, the prevalence of diastolic hypertension in obese children was $8.3 \%$ as compared to $0.7 \%$ in normal weight children [Table 6].

In the present study, out of 2800 school children screened, 33 had sustained Hypertension. In those 33 children 50\% showed elevated $\left(>95^{\text {th }}\right.$ centile) Triglyceride levels and 3 children had (Bilateral $\{\mathrm{B} / \mathrm{L}\}$ polycystic kidney) on ultra sonography. The associated risk factors were shown in Table 7.

\section{DISCUSSION}

The present cross sectional study was undertaken to find out prevalence of obesity \& its correlation with hypertension in school going children and adolescents of north Karnataka part of India. There is lack of studies done in Karnataka on childhood obesity and related complications in available literature.

There are various studies done on prevalence of Hypertension in obese school going children and results vary from $3.4 \%$ to $43 \% .^{[14-18]}$

\begin{tabular}{lcccc}
\multicolumn{5}{l}{ Table 3: Distribution of rural school children } \\
\multicolumn{5}{c}{ according BMI \& systolic blood pressure* } \\
\hline Normal (\%) & PHTN (\%) & HTN (\%) & Total \\
\hline Normal & $1345(97.3)$ & $10(0.8)$ & $12(0.9)$ & 1369 \\
OW & $16(69.5)$ & $5(21)$ & $2(8)$ & 23 \\
OB & $4(50.0)$ & $2(25.0)$ & $2(25.0)$ & 8 \\
Total & 1367 & 17 & 16 & 1400 \\
\hline
\end{tabular}

*Values are in absolute no. \& percentage

\begin{tabular}{lcccc}
\multicolumn{5}{l}{ Table 4: Distribution of urban school children } \\
\multicolumn{5}{c}{ according BMI \& systolic blood pressure* } \\
\hline Normal & $1285(97.5)$ & $9(0.6)$ & $16(1.2)$ & 1318 \\
OW & $50(86.2)$ & $3(5.17)$ & $6(8.62)$ & 58 \\
OB & $18(83.3)$ & $2(8.34)$ & $5(16.66)$ & 24 \\
Total & 1353 & 14 & 27 & 1400 \\
\hline
\end{tabular}

* Values are in absolute no. \& percentage

\begin{tabular}{|c|c|c|c|c|}
\hline & Normal (\%) & PHTN (\%) & HTN (\%) & Total \\
\hline Normal & $1354(98.6)$ & $12(0.8)$ & $3(0.2)$ & 1369 \\
\hline OW & $17(73.9)$ & $4(17.3)$ & $2(8.6)$ & 23 \\
\hline OB & $5(62.5)$ & $2(25)$ & $1(12.5)$ & 8 \\
\hline Total & 1374 & 18 & 06 & 1400 \\
\hline
\end{tabular}

\begin{tabular}{lcccc}
\multicolumn{5}{l}{ Table 6: Distribution of urban school children } \\
\multicolumn{5}{c}{ according BMI \& diastolic blood pressure* } \\
\hline Normal & $1289(97.7)$ & $19(1.4)$ & $10(0.7)$ & 1318 \\
OW & $49(89.6)$ & $4(6.8)$ & $5(9.2)$ & 58 \\
OB & $18(79.1)$ & $3(12.5)$ & $3(10.5)$ & 24 \\
Total & 1356 & 26 & 18 & 1400 \\
\hline
\end{tabular}

*Values are in absolute no. \& percentage 


\begin{tabular}{|c|c|c|c|c|c|c|}
\hline Age (years) & OW & OB & Family history of HTN & Lipid profile (TG $>95^{\text {th }}$ centile) & USG abdomen & Total \\
\hline 10 & 2 & 1 & 1 & 1 & $\mathrm{~N}$ & 5 \\
\hline 12 & 2 & 1 & - & 2 & 1 (B/L polycystic kidney) & 6 \\
\hline 13 & 3 & 2 & 2 & 5 & $\mathrm{~N}$ & 9 \\
\hline 15 & 5 & 4 & 2 & 5 & 2 (B/L polycystic kidney) & 13 \\
\hline
\end{tabular}

*Values are in absolute no. (No. of students)

Prevalence of hypertension in the present study was found to be more significant in overweight and obese children as compared to normal weight children both in urban and rural population. This relationship has been reported by other studies as well. ${ }^{[19-25]}$ Studies from India have also shown similar trends. ${ }^{[19,26-28]}$

Obesity acts as a risk factor for various disorders including cardiovascular and cerebrovascular system. ${ }^{[29,30]}$ These disorders lead to high mortality and morbidity. Today about $70 \%$ of deaths occur because of these cardiovascular pathologies in India. ${ }^{[31]}$ Because even small increase in BMI of high risk patient can increase mortality rate by several fold, it is essential to start the preventive measures in early part of life i.e. in childhood only. Our data of prevalence of obesity \& hypertension in childhood can help to initiate this primordial prevention.

It is also clear from our study that the prevalence of overweight and obesity is more in urban school children than rural children population. There is major effect of rapid economic growth on the nutritional status of many countries. ${ }^{[32]}$ Nutritional status has been improved a lot and because of this obesity has increased markedly in most Asian countries. ${ }^{[33]}$ A similar nutritional transition is under way in India as well. ${ }^{[34]}$ In addition to this, the present technological system also contributes to the rapidly rising prevalence of obesity. The sedentary lifestyle of children and adolescents have been attributed mainly to television viewing, computer games, internet, overemphasis on academic excellence, unscientific urban planning and ever-increasing automated transport. ${ }^{[35]}$ Unhealthy eating habits and physical inactivity are the major culprits. ${ }^{[35]}$ The difference in prevalence and trends of overweight among rural and urban schools demonstrated by this study could be due to these influences.

But in rural school children also there is noticeable change in prevalence of obesity and overweight. Change in Lifestyle methods have a major effect on children from rural population is evident from this finding.

In our study, we found that, the prevalence of hypertension was $1.1 \%$ in rural school children and $1.9 \%$ in urban school children. A wide range of prevalence of hypertension has been recorded in different studies ranging from 1 to $16.2 \%$. This diversity of prevalence of hypertension is mainly due to different criteria adopted for defining hypertension and basic racial subgroups related to geographic factors. ${ }^{[36]}$

In our study, a total 2800 school children were screened out of which 16 children had sustained Hypertension. The prevalence of HT in urban population was found to be more than rural population. The contributing factors could be dietary habits like junk foods, lack of physical activity and peer pressures. ${ }^{[35]}$ Similar, findings were noted about diastolic HT. When the associated risk factors were assessed in these 16 students, various factors were observed. They were mainly, family history of hypertension, elevated TGs levels and obesity. Similar, findings were also noted by studies done by Naveen Kumar et al.. ${ }^{[17]} \&$ V.K. Agarwal et al. ${ }^{[37]}$

Our study has some limitations, like we measured body mass index (BMI) as an obesity marker. We did not consider measurements of waist-hip ratio and skin-fold thickness which are direct measurement of fat mass. The energy intake, energy expenditure which lies in etiology of obesity, we did not measured it. In case of BP measurement, we did not consider the salt intake by individual, diet, physical activity. These factors can affect the data.

Early detection of obesity and hypertension is very crucial. Obesity and hypertension start in initial period of life. So the intervention to prevent the related morbidities like stroke, Myocardial Infarction, respiratory disorders should be started in the childhood only. The findings of this study will help to establish preventive measures in the developing part of India.

\section{CONCLUSION}

This study revealed that prevalence of hypertension was significantly higher in overweight and obese compared to children with Normal BMI indicating obesity as a risk factor for hypertension. The prevalence of overweight and obesity is more in urban school children than rural children population. Current lifestyle methods in urban area like physical inactivity, unhealthy eating habits like junk food are the major causative factors for this increasing trend in urban area. So in feature to prevent morbidities of obesity such as hypertension, early intervention strategies for promoting healthy eating, physical activities and health education should be undertaken from school age group.

\section{REFERENCES}

1. Ramachandran A, Snehalatha C, Vinitha R, Thayyil M, Kumar CK, Sheeba $\mathrm{L}$, et al. Prevalence of overweight in urban Indian adolescent school children. Diabetes Res Clin Pract 2002;57:185-90.

2. Kapil U, Singh P, Pathak P, Dwivedi SN, Bhasin S. Prevalence of obesity among affluent adolescent school children in Delhi. Indian Pediatr 2002;39:365-8.

3. Sidhu S, Kaur N, Kaur R. Overweight and obesity in affluent school children. Ann Hum Biol 2006;33:255-9.

4. Chhatwal J, Verma M, Rair SK. Obesity among pre-adolescent and adolescents of a developing country (India). Asia Pac J Clin Nutr 2004;13:231-3. 
5. Ross JG, Pate RR, Lohman TG, Christenson GM. Changes in the body composition of children. J Phys Educ Recreat Dance 1987;58:74-7.

6. Sorof JM, Poffenbarger T, Franco K, Bernard L, Portman RJ. Isolated systolic hypertension, obesity, and hyperkinetic hemodynamic states in children. J Pediatr 2002;140:660-6.

7. Dietz WH, Bandini LG, Gortmaker S. Epidemiologic and metabolic risk factors for childhood obesity. Prepared for Fourth congress on Obesity Research, Austria. Klin Pediatr 1998;202:69-72.

8. Gortmaker SL, Dietz WH Jr, Cheung LW. Inactivity, diet and the fattening of America. Am Diet Assoc 1990; 90:1247-55.

9. Riva P, Martini G, Rabbia F, Milan A, Paglieri C, Chiandussi L, et al. Obesity and autonomic function in adolescence. Clin Exp Hypertens 2001;23:57-67.

10. World Health organization. WHO Child Growth Standards. Available from: http://www.who.int/childgrowth/standards/chart catalogue/en/index.html. Last accessed on $12^{\text {th }}$ May 2013.

11. Barlow SE, Dietz WH. Obesity evaluation and treatment: Expert Committee recommendations. The Maternal and Child Health Bureau, Health Resources and Services Administration and the Department of Health and Human Services. Pediatrics 1998;102:E29.

12. National High Blood Pressure Education Program Working Group on High Blood Pressure in Children and Adolescents. The Fourth Report on the diagnosis, evaluation and treatment of high blood pressure in children and adolescents. Pediatrics 2004;114:555-75.

13. Update on the 1987 Task Force Report on High Blood Pressure in Children and Adolescents: A working group report from the National High Blood Pressure Education Program. National High Blood Pressure Education Program Working Group on Hypertension Control in Children and Adolescents. Pediatrics 1996;98:649-58.

14. Chatwal J, Verma, George SM. Obesity and hypertension in children. Indian Pediatrics 1994;31:1065-9.

15. Gupta AK, Ahmed AJ. Childhood Obesity and Hypertension. Indian Pediatr 1990;27:333-7.

16. Sorof JM, Turner J, Martin DS, Garcia K, Garami Z, Alexandrov $\mathrm{AV}$, et al. Cardiovascular risk factors and sequelae in hypertensive children identified by referal versus school based screening. Hypertension 2004;43:214-8.

17. Kumar N. Prevalence of sustained hypertension and obesity in urban and rural school going children in Ludhiana. Indian Heart J 2004;20:335-42.

18. Urrutia-Rojas X, Egbuchunam CU, Bae S, Menchaca J, Bayona M, Rivers PA, et al. High blood pressure in school children. BMC Pediatr 2006;6:32.

19. Verma M, Chhatwal J, George SM. Obesity and hypertension in children. Indian Pediatr 1994;31:1065-9.

20. Elcarte Lopez R, Villa Elizaga I, Sada Goni J, Gasco Eguiluz M, Oyarzabal Irigoyen $\mathrm{M}$, Sola Mateos $\mathrm{A}$, et al. Prevalence of arterial hypertension, hyperlipidemia and obesity in the infant-child population of Navarra. Association of risk factors. An Esp Pediatr 1993;38:428-36.

21. Guillaume M, Lapidus L, Beckers F, LambertA, Bjorntorp P. Cardiovascular riskfactors in children from the Belgian province of Luxembourg. The Belgian Luxembourg Child Study. Am J Epidemiol 1996;144:867-80.

22. Macedo ME, Trigueiros D, de Freitas F. Prevalence of high blood pressure in children and adolescents. Influence of obesity. Rev Port Cardiol 1997;16:27-8.

23. Freedman DS, Dietz WH, Srinivasan SR, Berenson GS. The relation of overweight to cardiovascular risk factors among children and adolescents: The Bogalusa Heart Study. Pediatrics 1999;103:1175-82.
24. Morrison JA, Barton BA, Biro FM, Daniels SR, Sprecher DL. Overweight, fat patterning, and cardiovascular disease risk factors in black and white boys. J Pediatr 1999;135:451-7.

25. Sorof JM, Poffenbarger T, Franco K, Bernard L, Portman RJ. Isolated systolic hypertension, obesity, and hyperkinetic hemodynamic states in children. J Pediatr 2002;140:660-66.

26. Mohan B, Kumar N, Aslam N, Rangbulla A, Kumbkarni S, Sood NK, et al. Prevalence of sustained hypertension and obesity in urban and rural school going children in Ludhiana. Indian Heart J 2004;56:310-14.

27. Anand NK, Tandon L. Prevalence of hypertension in school going children. Indian Pediatr 1996;33:377-81.

28. Gupta AK, Ahmad AJ. Childhood obesity and hypertension. Indian Pediatr 1990;27:333-37.

29. Ko GT, Chan JC, Woo J, Lau E, Yeung VT, Chow CC, et al. Simple anthropometric indexes and cardiovascular risk factors in Chinese. Int $\mathrm{J}$ Obes Relat Metab Disord 1997;21:995-1001.

30. Oh SW, Shin SA, Yun YH, Yoo T, Huh BY. Cut-off point of BMI and obesity related comorbidities and mortality in middle-aged Koreans. Obes Res 2004;12:2031-40.

31. World Health Organization. Preventing chronic diseases: A vital investment. World Global Report. Geneva: World Health Organization; 2005.

32. World Health Organization. Diet, nutrition and prevention of chronic diseases. Geneva: WHO; 2003.

33. Popkin BM, Doak CM. The obesity epidemic is a worldwide phenomenon. Nutr Rev 1998;56:106-14

34. Griffiths PL, Bentley ME. The nutrition transition is underway in India. $J$ Nutr 2001;131:2692-700.

35. Bar-Or O, Foreyt J, Bouchard C, Brownell KD, Dietz WH, Ravussin E, et al. Physical activity, genetic, and nutritional considerations in childhood weight management. Med Sci Sports Exerc 1998;30:2-10.

36. Goldring D, Londe S, Sivakoff M, Hernandez A, Britton C, Choi S. Blood pressure in high school population. J Pediatr 1977;91:884-9.

37. Agarwal VK. Blood pressure profile in Children aged 3-15 yrs. Indian Paediatr 1984;21:41-8.

38. Chadha SL, Tandon R, Shekawat S, Gopinath N. An epidemiological study of blood pressure in school children (5-14 years) in Delhi. Indian Heart J 1999;51:178-82.

39. Powe C, Lake JK, Cole TJ. Measurement and long term health risks of child and adolescent fatness. Int J Obes Relat Metab Disord 1997;21: 507-26.

40. Bouchard C, James WP. Hand book of Obesity. New York: Marcel Dekker: $2^{\text {nd }}$ Edition 2004

41. Must A, Strauss RS. Risks and consequences of childhood adolescent obesity. Int J Obes RelatMetabDisord 1999;23:S2-11.

42. Lurbe E, Cifkova R, Cruickshank JK, Dillon MJ, Ferreira I, Invitti C, et al. Management of high blood pressure in children and adolescents: Recommendations of the European Society of Hypertension. J Hypertens 2009; 27:1719-42.

How to cite this article: Baradol RV, Patil S, Ranagol A. Prevalence of overweight, obesity and hypertension amongst school children and adolescents in North Karnataka: A cross sectional study. Int J Med Public Health 2014;4:260-4.

Source of Support: The present study was funded by B.L.D.E. University, Bijapur, Conflict of Interest: None declared. 